\title{
Clinical use of topical thrombin as a surgical hemostat
}

\author{
Wesley K Lew' \\ Fred A Weaver ${ }^{2}$ \\ 'University of Southern California, \\ Department of Surgery, Los Angeles, \\ CA, USA; ${ }^{2}$ CardioVascular Thoracic \\ Institute at the University of Southern \\ California, Los Angeles, CA, USA
}

\begin{abstract}
When surgical ligation of bleeding fails, or is not possible, surgeons rely on a number of hemostatic aids, including thrombin. This review discusses the history, pharmacology and clinical application of thrombin as a surgical hemostat. The initial thrombin was bovine in origin, but its use has been complicated by the formation of antibodies that cross react with human coagulation factors. This has been associated with life threatening bleeding and in some circumstances anaphylaxis and death. Human thrombin, isolated from pooled plasma of donors, has been developed in an effort to minimize these risks, but its downside is the potential of transmitting blood-borne pathogens and limited availability. Recently a recombinant thrombin has been developed and approved for use by the FDA. It has the advantage of being minimally antigenic and devoid of the risk if viral transmission. Thrombin is often used in conjunction with other hemostatic aids, including absorbable agents (like gelfoam, collagen, and cellulose), and with fibrinogen in fibrin glues. The last part of this review will discuss these agents in detail, and review their clinical applications.
\end{abstract}

Keywords: bovine, recombinant, human, thrombin, antigenicity, antibodies

\section{Introduction}

In any surgical procedure, hemostasis is vital to success. When surgical ligation of bleeding fails, or is not possible, surgeons rely on a number of hemostatic aids. One such hemostatic ancillary is thrombin.

Thrombin has a long history as a vehicle to affect hemostasis. Descriptions can be found in the European literature as early as 1892 for the use of thrombin (Brister et al 1994). Early on, thrombin was used by barbers and boxers, for hemostasis of shaving cuts and fight lacerations. Records citing thrombin use in surgery date back to the 1940s. Since then its use has grown exponentially, and now thrombin is used in more than 1 million patients in the United States each year at a cost of US\$250 million (Lawson 2006). Recently there have been new developments in thrombin, namely FDA approval in human thrombin, and development of a recombinant thrombin.

This review will discuss the mechanism by which thrombin acts, the history of bovine thrombin, the development of human thrombin, methods of thrombin delivery in clinical applications, and finally the future of thrombin in regards to recombinant technologies.

\section{Mechanism of thrombin}

Thrombin has a number of well studied biological activities, which serve to achieve coagulation and hemostasis. With tissue injury and bleeding, exposed collagen and released tissue factor cause activation of the intrinsic and extrinsic coagulation pathways. Both pathways lead to activation of factor $\mathrm{X}$ which along with activated factor $\mathrm{V}$ forms a complex that cleaves the prothrombin protein into the active thrombin molecule. Thrombin production is the final coagulation step required to cleave fibrinogen into fibrin 
which provides a hemostatic lattice for platelet aggregation and thrombus formation at the site of injury (Figure 1).

In addition to the coagulation cascade, thrombin can act directly on a number of cell types. At the smooth muscle cell, it causes vasoconstriction which aids in hemostasis. By activating platelets it promotes their aggregation at the site of thrombus. Activated thrombin also acts as a mitogen and chemoattractant for neutrophils, fibroblasts, and even induces the formation of VEGF for tissue and vascular remodeling and repair (Brister et al 1994; Patterson et al 2001; Lawson 2006).

Interestingly, thrombin not only promotes coagulation, but it can also activate the anticoagulant system through protein $\mathrm{C}$. When there is vascular injury the procoagulant effects of thrombin are activated as described above. However, when there is no vascular disruption, thrombin will interact with thrombomodulin to activate protein $\mathrm{C}$ to improve circulation through an anticoagulant effect (Dahlback 2000).

Through all of these varied actions, thrombin promotes and modulates coagulation. For the purpose of this treatise we will confine the discussion to its pro-thrombotic role and how that has been harnessed to limit bleeding in a variety of surgical procedures.

\section{Bovine thrombin}

The initial source of thrombin was from a bovine origin and its effectiveness at facilitating surgical hemostasis resulted in it quickly becoming a popular surgical ancillary.
With increased usage and thus patient exposure, isolated case reports surfaced suggesting that bovine thrombin may be operational in surgically related bleeding abnormalities. The first report in the literature questioning bovine thrombin safety was in 1989 by Flaherty et al (1989). He identified four patients with prior bovine thrombin exposure and unexplained prolonged thrombin times (greater than 300 seconds). Mixing studies suggested the presence of an inhibitor, and the thrombin test times were able to be corrected if human thrombin was substituted for bovine thrombin in the test reagents. The antibodies to bovine thrombin were isolated from the patients, and found to prolong the thrombin times if added to the plasma of normal patients.

The actual antibody generated by bovine thrombin exposure was further characterized by Zehnder in 1990 (Zehnder and Leung 1990). He reported a 65-year-old patient who underwent a cardiac procedure complicated by uncontrolled and persistent postoperative bleeding. The patient's factor $\mathrm{V}$ activity was $1 \%$ of normal and was not corrected by mixing with normal plasma, demonstrating the presence of an inhibitor against factor $\mathrm{V}$. This inhibitor was found to be an antibody of bovine factor $V$ that cross reacted with the patient's own factor V (Figure1). The source of the bovine factor $\mathrm{V}$ was from the bovine thrombin preparation which contained not only thrombin, but other bovine plasma proteins. Similar case reports soon surfaced documenting coagulopathy that was associated with bovine thrombin

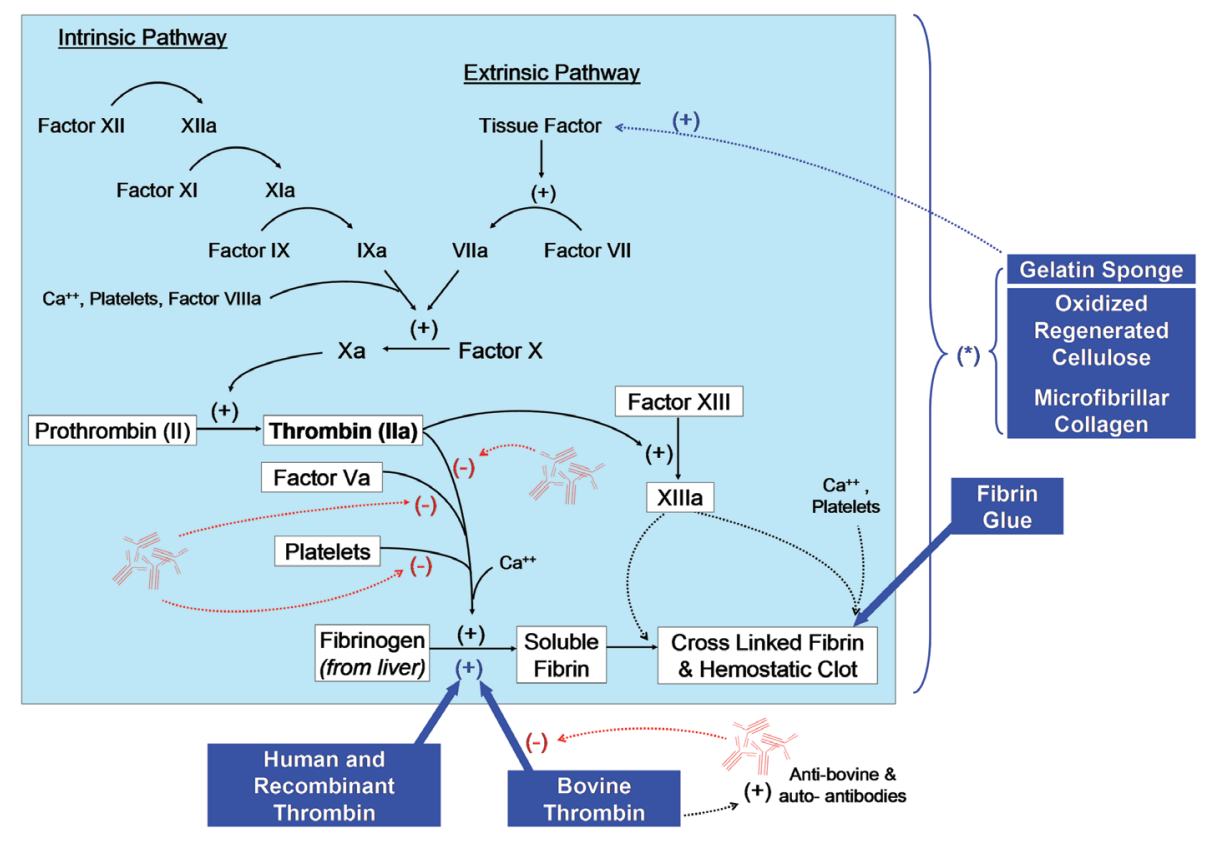

Figure I Diagram of coagulation cascade. Blue boxes and arrows include various hemostatic agents with their mechanism of actions. $(+)$ these agents affect the entire coagulation cascade by concentration and creating of a matrix for coagulation factors at the bleeding site. Red arrows indicate the inhibition caused by bovine generated antibodies to thrombin, factor $V$, and platelet antiphospholipids. 
exposure. Additional bovine thrombin antibodies have been isolated, including antibodies to the bovine thrombin itself (Lawson 1990; Rapaport et al 1992).

In 1994, Ortel reported a case series of four patients with acquired factor $\mathrm{V}$ inhibitors from presumed repeated exposure to bovine thrombin preparations. The authors reviewed the literature and identified an additional thirteen patients with documented bovine thrombin preparation induced factor $\mathrm{V}$ antibodies. They noted that even though all seventeen patients had the factor $\mathrm{V}$ inhibitor, each patient had a different clinical course ranging from asymptomatic to life threatening hemorrhage (Ortel et al 1994). Despite the accumulating data concerning factor $\mathrm{V}$ antibody generation, the commercial use of bovine thrombin continued and in fact increased. However, by 1996 the weight of the evidence resulted in the FDA attaching a Black Box drug warning label to all bovine thrombin containing products (Lawson 2006).

In addition to hemorrhage, case reports of thrombotic reactions to antibodies generated by bovine thrombin preparations began to surface. In a study with 88 hemodialysis patients (Sands et al 2000) and another case report with 1 cardiac patient (Fastenau et al 1999), the authors demonstrated certain patients exposed to bovine thrombin preparations could developed antiphospholipid antibodies causing subsequent thrombosis. More bovine thrombin induced antibodies continued to be discovered, as mice experiments by Schoenecker et al in 2001 demonstrated autoantibodies similar to those found in autoimmune disorders like SLE could be caused by bovine thrombin exposure (Schoenecker et al 2001).

To better delineate the incidence of antibody formation following bovine thrombin exposure, Ortel in 2001 prospectively studied 151 patients undergoing cardiac surgery. The authors found more than $95 \%$ of patients developed a seropositive response to bovine coagulation proteins, and 51\% manifested elevated antibody levels to the corresponding human coagulation proteins after bovine thrombin exposure. Furthermore, 15 of these 151 patients had previous surgeries and were positive for preoperative antibodies to bovine proteins from assumed previous thrombin exposure. These 15 had significantly more adverse effects $(73.3 \%)$ than those without previous surgery or antibodies (33.8\%), $\mathrm{p}=0.0042$ (Ortel et al 2001).

In 2002, another review by Streiff documented 126 cases of factor $\mathrm{V}$ inhibitors found in the medical literature. These cases included patients with spontaneous and bovine thrombin induced factor $\mathrm{V}$ inhibitors. Interestingly a majority of the cases were found in the previous 10 years indicating an increasing incidence. Fifty-eight of the patients were bovine thrombin-induced only, and 33\% developed some sort of bleeding complication (Streiff and Ness 2002).

Almost every surgical specialty has had a case study or series of adverse events related to the use of bovine thrombin; neurosurgery (Spero 1993; Banninger et al 1993; Poynton et al 2003), pediatric surgery (Muntean et al 1994; Israels and Israels 1994; Israels and Leaker 1997; Savage et al 2007), cardiac surgery (Banninger et al 1993; Berruyer et al 1993; Lawson et al 2005), ob-gyn (Adams et al 2001), vascular (Kajitani et al 2000; Sarfati et al 2004), and nephrology (Pavlovich et al 2001). Despite this evidence bovine thrombin continues to be widely used, and its market has grown to a reported US\$247 million in 2007 (Timmerman 2007). The major reason for the continued popularity of bovine thrombin was the lack of an alternative thrombin preparation. However, human thrombin and more recently a recombinant thrombin are now available and pose a challenge to bovine thrombin in the surgical ancillary market.

\section{Human thrombin}

The adverse immunological effects associated with bovine thrombin have lead to the development of thrombin from alternative sources. Human derived thrombin is one such alternative. Human thrombin is isolated from pooled human plasma donors at US licensed collection centers. All donors are tested for blood-borne diseases (HIV, hepatitis, parvovirus B19). The plasma is then processed through a series of separation and filtration steps followed by incubation of the solution with calcium chloride to isolate and activate prothrombin to thrombin. The solution subsequently undergoes ultrafiltration, vapor heat treatment, solvent-detergent treatment, sterile filtration, and freeze-drying.

The vapor heat and solvent-detergent treatment steps used in the manufacturing process have been shown to be capable of significant viral reduction. No procedure, however, has been shown to be completely effective in removing viral infectivity from derivatives of human plasma. Therefore although relatively safe, there is still no assurance that human thrombin is completely free of blood-borne pathogens (Jackson 2001; Baxter 2007; Heffernan et al 2007; Omrix Biopharmaceuticals 2007). An additional issue is the finite availability of human derived blood products and whether the supply can be sufficient for the potential demand.

In 2007, the FDA finally approved the first stand alone human thrombin preparation, Evithrom ${ }^{\circledR}$ (Omrix Biopharmaceuticals, Ltd, New York, NY, USA) (US Food and Drug Administration 2007). Previously, human thrombin 
was only used in FDA approved combination products, namely Floseal ${ }^{\circledR}$ (Baxter; Deerfield, IL, USA), and the fibrin glues (to be discussed in greater detail later).

Results from an unpublished clinical trial of Evithrom ${ }^{\circledR}$ versus bovine thrombin can be found in the packet insert for Evithrom $^{\circledR}$. In a phase III, prospective, randomized, controlled, double-blinded study of 305 subjects at 22 centers in the US, subjects undergoing elective cardiovascular, neurological (spinal) or general surgical procedures were randomized to treat oozing or bleeding (of mild intensity that could not be controlled by other surgical techniques) with bovine thrombin and Surgifoam ${ }^{\circledR}$ (Johnson and Johnson Wound Management; Somerville, NJ, USA) or Evithrom ${ }^{\circledR}$ and Surgifoam ${ }^{\circledR}$. Treatment with Evithrom ${ }^{\circledR}$ was as successful as treatment with bovine thrombin in achieving the primary efficacy endpoint: hemostasis within 10 minutes of product application. The secondary efficacy endpoint of hemostasis within 6 and 3 minutes of product application also was achieved. There was no difference in safety between the two groups.

In the Evithrom ${ }^{\circledR}$ group there were $17 \%$ serious adverse events as compared to $11 \%$ in the bovine thrombin group. Two subjects $(1.3 \%)$ in the Evithrom ${ }^{\circledR}$ group experienced a severe adverse event: respiratory arrest and post-procedural hematoma in one subject and an extradural hematoma in the other. Three subjects in the bovine thrombin group experienced severe adverse events: hyperhidrosis, pyrexia, and post-procedural hematoma. None of the adverse events reported was considered causally related to Evithrom ${ }^{\circledR}$ or bovine thrombin administration. No deaths were reported during the study period (Omrix Biopharmaceuticals 2007).

\section{Recombinant human thrombin (rhThrombin)}

The development of a recombinant human thrombin, Recothrom $^{\circledR}$ (Zymogenetics Inc; Seattle, Washington, USA), provides a manufactured source of thrombin that is devoid of the risks of antibody development found with bovine thrombin or the theoretic risks of viral transmission with human derived thrombin. Recombinant thrombin has the identical amino acid sequence as human thrombin, and is made from a genetically modified Chinese hamster ovary cell line. Although hypothetically, Recothrom ${ }^{\circledR}$ is free from infectious agents, there is still a final purification process with solvent-detergent treatment and nano-filtration. This product was approved by the US FDA in January 2008 (Zymogenetics 2008).

Phase 1 animal trials demonstrated rhThrombin to be safe in animal subjects (Heffernan et al 2007). Phase 2 trials have been completed comparing the safety profile of rhThrombin to placebo. One hundred thirty patients undergoing AV graft, liver resections, peripheral artery bypass, and spinal surgery were randomized to either rhThrombin or placebo soaked in Gelfoam $^{\circledR}$ (Pharmacia and Upjohn, Briggewater, NJ, US) or Surgifoam $^{\circledR}$. No patterns of treatment-related adverse events were associated with rhThrombin. Recombinant thrombin induced minimal antibody generation and no antibody mediated reactions to coagulation proteins were documented (Chapman et al 2006).

A recently published phase 3 trial compared the efficacy, safety, and antigenicity of rhThrombin versus bovine thrombin. In 401 patients undergoing liver resection, spine, peripheral arterial bypass, and dialysis access surgery were randomly assigned to either rhThrombin or bovine thrombin (bThrombin) for surgical hemostasis. A gelatin sponge was used as a carrier. Hemostasis was achieved at the time-tohemostasis evaluation site within 10 minutes in $95 \%$ of patients in each treatment group. Overall complications, including operative mortality, adverse events, and laboratory abnormalities, were similar between groups. However, in terms of antigenicity, $21.5 \%$ of the patients receiving bovine thrombin developed antibodies to the product whereas only $1.5 \%$ in the rhThrombin group developed antibodies to rhThrombin, $\mathrm{p}<0.0001$.

In post hoc analysis, those that developed anti-bThrombin antibodies $(n=43)$ had a numerically higher incidence of bleeding, thromboembolic events, hypersensitivity, and abnormal aPTT compared with those in the bThrombin group that did not develop antibodies $(n=157)$. This increase was not seen in those with anti-rhThrombin antibodies $(n=3)$ compared with those in the rhThrombin group that did not develop antibodies $(n=195)$ (Chapman et al 2007).

Currently in publication is the companion study for the vascular subgroup in the previously mentioned phase 3 trial. In this population, the improved antigenicity profile was again noted for rhThrombin versus bThrombin, and in the peripheral arterial bypass subgroup the time to hemostasis was actually better in the rhThrombin group when compared to the bThrombin group (Weaver et al 2008).

\section{Mechanisms for delivery}

Thrombin is used predominantly as a topical agent for bleeding that cannot be controlled with suture ligation or electrocautery. It is particularly useful in neurosurgical applications near the spine, in liver surgery where there is raw liver surface bleeding, and in vascular surgery where needle holes in PTFE grafts continue to ooze. 
There are many ways thrombin is used during a surgical procedure to effect hemostasis. It can be used alone, in combination with an absorbable hemostatic carrier, or in a manufactured combination with fibrin. Given the discussion previously, it is important to know the source of thrombin (bovine, human, recombinant), and the source of any other additives in the manufactured preparations.

\section{Thrombin use alone}

In the past pure thrombin was only available from a bovine source, and manufactured as thrombin-JMI ${ }^{\circledR}$ (King Pharmaceuticals, Inc, Bristol, TN, US). Now there is also an FDA approved human thrombin $\left(\right.$ Evithrom $\left.^{\circledR}\right)$ and just recently, a recombinant thrombin $\left(\right.$ Recothrom $\left.^{\circledR}\right)$.

Thrombin-JMI ${ }^{\circledR}$ and Recothrom ${ }^{\circledR}$ are stored at room temperature, as a powder, which is reconstituted with saline into solution for use. (Zymogenetics 2008, King Pharmaceuticals Inc 2007). Evithrom ${ }^{\circledR}$ is packaged as a solution, and stored in a freezer. Otherwise it can be refrigerated for up to 30 days, or kept at room temperature for up to 24 hours. (Omrix Biopharmaceuticals 2007). All stand alone thrombin, regardless of origin, are applied as a solution and can be cumbersome for topical application unless sprayed into a mist, or used with another carrier (like the absorbable hemostatic agents) or in combination with fibrinogen to create a "glue".

\section{Thrombin and absorbable hemostatic agents}

Absorbable hemostatic agents include: gelatin sponge, oxidized regenerated cellulose, and microfibrillar collagen. These agents can be used alone or in combination with thrombin. They all are porous structures that provide a framework for platelet and coagulation factor activation (Figure $1[+]$ ). This implies there must be functional coagulation factors present for clot to form (Wagner et al 1996).

One issue with these agents is there porous nature can cause expansion. In closed spaces like the spinal canal, cases have been reported where this expansion leads to spinal cord compression injuries. (Sabel and Stummer 2004). In addition, there is also the possible risk of embolization if applied to open arterial bleeding rather than diffuse oozing. However, these risks are low and the user friendly nature of the absorbable hemostatic agents makes them a popular surgical ancillary which are widely and frequently used by most surgical specialties.

\section{Gelatin sponge}

Gelatin sponges for surgical use were first introduced in the 1940s for neurosurgical procedures. The gelatin consists of a purified pork or bovine skin. Its surface causes activation of the intrinsic coagulation pathway but its main effect is its ability to absorb approximately 45 times its weight, expanding to approximately $200 \%$ of its initial volume. This facilitates a concentration of coagulation factors at the site of bleeding. A number of manufactured versions exist, and it is available as a sheet, powder, prepackaged in a syringe, or even prepackaged with thrombin.

Gelfoam $^{\circledR}$ (Pharmacia and Upjohn, Briggewater, NJ, US) comes in sheets, Surgifoam ${ }^{\circledR}$ (Johnson and Johnson Wound Management) is also a sheet or powder, and Surgiflo ${ }^{\circledR}$ (Johnson and Johnson Wound Management) is available in an applicator syringe that allows for the addition of any thrombin solution. All these products carry a theoretic risk for antigenicity given they are derived from non-human sources, but to date no adverse events have been linked to gelatin formulations.

Floseal ${ }^{\circledR}$ (Baxter; Deerfield, IL, US) is a prepackaged gelatin matrix with a separate human thrombin component. This human thrombin is a powder that is reconstituted with a calcium chloride solution then mixed with the gelatin matrix in a delivery syringe. Initially, both the gelatin and thrombin were from bovine origin, but in 2002 Baxter replaced the bovine thrombin with pooled human plasma thrombin. (Baxter 2005).

\section{Oxidized regenerated cellulose}

Introduced in the $1940 \mathrm{~s}$, as well, oxidized regenerated cellulose is now marketed as Surgicel ${ }^{\circledR}$ (Johnson and Johnson Wound Management). This product looks like cloth, and in fact is basically treated cotton. Oxidation converts the hydroxyl groups into carboxylic acid, and this allows for denaturation of blood proteins initiating hemostasis. Regeneration implies the cotton is initially dissolved then extruded as a continuous fiber which can then be manufactured into desired configurations. Surgicel Nu-Knit ${ }^{\circledR}$ is made into thick sheets, and Surgicel Fibrillar ${ }^{\circledR}$ is a more loosely woven structure arrangement. Of note Surgicel ${ }^{\circledR}$ is bacteriostatic and absorbs in 1-2 weeks. (Frantz et al 1944).

\section{Microfibrillar collagen}

Avitene $^{\circledR}$ (Bard; Cranston, RI, US) and INSTAT ${ }^{\circledR}$ (Johnson and Johnson Wound Management) are microfibrillar collagen agents. Bovine collagen is processed and purified into waterinsoluble acid salts that initiate platelet activation. Avitene ${ }^{\circledR}$ can be manufactured into small particles, sheets, and sponges.

\section{Thrombin and fibrinogen (fibrin glue)}

Fibrin glues contain thrombin and fibrinogen. When combined the fibrinogen is activated by thrombin and 
converted into fibrin monomers. This forms an adhesive glue at the tissues applied. The fibrin monomers go on to interact with the patient's own factor XIII and calcium to convert the final product into a fibrin polymer that allows for platelet activation and aggregation with subsequent hemostasis (Figure 1).

Fibrin glues come packaged with a dual chamber syringe that allows for the combination of the thrombin and fibrinogen after the plunger is depressed. Commercially available products include Tissee ${ }^{\circledR}$ (Baxter; Deerfield, IL, US) and Evicel $^{\circledR}$ (Johnson and Johnson Wound Management). All components in Evicel ${ }^{\circledR}$, formerly Crosseal ${ }^{\circledR}$, are human derived (Johnson and Johnson Wound Management 2007). Tissee ${ }^{\circledR}$ uses thrombin and fibrinogen derived from human sources, but there is an additional fibrinolysis inhibitor added to the fibrinogen component to prevent premature fibrinolysis after the fibrin glue is applied. This fibrinolysis inhibitor was originally extracted from bovine, but in 2007 this was replaced with a synthetic inhibitor, rendering Tissee ${ }^{\circledR}$ bovine free (Baxter 2007).

\section{Indications for use}

All the above combination products are effective and none have demonstrated singular superiority with the exception of a few specific surgical settings. Currently, bovine thrombin is the most common thrombin used alone or in combination with a gelatin sponge. Manufactured combination products such as the fibrin glues and Floseal ${ }^{\circledR}$ contain almost exclusively human thrombin. Recombinant thrombin which was just recently approved may replace bovine or human thrombin in many of these applications, but to what degree remains to be seen.

For any given surgical procedure, which thrombin or combination product is mainly dependent on surgeon preference. In general, the stand alone thrombin spray is used to assist in hemostasis of large raw surface areas such as in the case of solid viscera injury and resection of retroperitoneal tumors. Gelatin/thrombin combinations are very helpful in achieving hemostasis in vascular and spinal procedures and the fibrin glues are most commonly used in reoperative cardiac procedures, complicated by persistent and difficult to control mediastinal bleeding. The effectiveness of the gelatin/thrombin combination to achieve hemostasis has been extensively studied and found to be quite effective. The different fibrin glues have also been studied in numerous surgical settings including liver resections (Schwartz et al 2004), vascular PTFE grafts (Glickman et al 2002; Taylor et al 2003), and even inguinal hernia repairs (Canonico 2003).

\section{Conclusions}

Thrombin has had a long history in surgical hemostasis, and has proven to be a useful and effective ancillary for surgical hemostasis. Early bovine thrombin formulations have been conclusively linked to the development of antibodies that cross react with multiple human coagulation proteins, factor $\mathrm{V}$ being the most important. These bovine induced antibodies to human coagulation factors have led to numerous cases of life threatening bleeding and other complications. The recent FDA approval of human thrombin has provided an alternative to bovine thrombin, but has the theoretic risk of viral transmission. The more recent development and FDA approval of a recombinant protein thrombin product provides yet another potential alternative, with equal efficacy to bovine thrombin, without the attendant risk of antigenicity (Chapman et al 2007).

\section{Disclosures}

Fred Weaver has served as a consultant for Zymogenetics and has received research grant support from Zymogenetics.

\section{References}

Adams JD, Jones S, Brost BC. 2001. Development of antibodies to topical bovine thrombin after abdominal hysterectomy. A case report. J Reprod Med, 46:909-12.

Banninger H, Hardegger T, Tobler A, et al. 1993. Fibrin glue in surgery: frequent development of inhibitors of bovine thrombin and human factor V. Br J Haematol, 85:528-32.

Baxter. Packet Insert for Floseal. Last updated March 2005. URL: http://www.baxter.com/products/biopharmaceuticals/downloads/ FloSeal_PI.pdf.

Baxter. Packet Insert for Tisseal. Last updated February 2007. URL: http://www.baxter.com/products/biopharmaceuticals/downloads/ Tisseel_PI.pdf.

Berruyer M, Amiral J, Ffrench P, et al. 1993. Immunization by bovine thrombin used with fibrin glue during cardiovascular operations. Development of thrombin and factor V inhibitors. J Thorac Cardiovasc Surg, 105:892-7.

Brister SJ, Ofosu FA, Buchanan MR. 1994. Thrombin: its key role in thrombogenesis : implications for its inhibition clinically. Boca Raton, FL: CRC Press.

Canonico S. 2003. The use of human fibrin glue in the surgical operations. Acta Biomed, 74(Suppl 2):21-5.

Chapman WC, Lockstadt H, Singla N, et al. 2006. Phase 2, randomized, double-blind, placebo-controlled, multicenter clinical evaluation of recombinant human thrombin in multiple surgical indications. J Thromb Haemost, 4:2083-5.

Chapman WC, Singla N, Genyk Y, et al. 2007. A phase 3, randomized, double-blind comparative study of the efficacy and safety of topical recombinant human thrombin and bovine thrombin in surgical hemostasis. J Am Coll Surg, 205:256-65.

Dahlback B. 2000. Blood coagulation. Lancet, 355:1627-32.

Flaherty MJ, Henderson R, Wener MH. 1989. Iatrogenic immunization with bovine thrombin: a mechanism for prolonged thrombin times after surgery. Ann Intern Med, 111:631-4.

Fastenau DR, Hormuth DA, McIntyre JA. 1999. Antiphospholipid antibodies in left-ventricular assist system recipients after exposure to topical bovine thrombin. Transplant Proc, 31:141-2. 
Frantz VK, Clarke HT, Lattes R. 1944. Hemostasis with absorbable gauze (oxidized cellulose). Ann Surg, 120:181-98.

Glickman M, Gheissari A, Money S, et al. 2002. A polymeric sealant inhibits anastomotic suture hole bleeding more rapidly than gelfoam/thrombin results of a randomized controlled trial. Arch Surg, 137:326-31; discussion 332.

Heffernan JK, Ponce RA, Zuckerman LA, et al. 2007. Preclinical safety of recombinant human thrombin. Regul Toxicol Pharmacol, 47:48-58.

Israels SJ, Israels ED. 1994. Development of antibodies to bovine and human factor $\mathrm{V}$ in two children after exposure to topical bovine thrombin. $\mathrm{Am}$ $J$ Pediatr Hematol Oncol, 16:249-54.

Israels SJ, Leaker MT. 1997. Acquired inhibitors to factors V and X after exposure to topical thrombin: interference with monitoring of low molecular weight heparin and warfarin. J Pediatr, 131:480-3.

Jackson MR. 2001. Fibrin sealants in surgical practice: An overview. Am J Surg, 182:1S-7S.

Johnson and Johnson Wound Management. Packet Insert for Evicel. Last updated June 2007. URL: http://www.vapr.com/public/USENG/ EVICEL_EPI.pdf.

Kajitani M, Ozdemir A, Aguinaga M, et al. 2000. Severe hemorrhagic complication due to acquired factor $\mathrm{V}$ inhibitor after single exposure to bovine thrombin product. J Card Surg, 15:378-82.

King Pharmaceuticals Inc. Package Insert for Thrombin-JMI. Last updated September 2007, URL: http://www.kingpharm.com/kingpharm/ uploads/pdf_inserts/Thrombin_Web_PI_2007-09.pdf.

Lawson JH, Pennell BJ, Olson JD, et al. 1990. Isolation and characterization of an acquired antithrombin antibody. Blood, 76:2249-57.

Lawson JH, Lynn KA, Vanmatre RM, et al. 2005. Antihuman factor V antibodies after use of relatively pure bovine thrombin. Ann Thorac Surg, 79:1037-8.

Lawson JH. 2006. The clinical use and immunologic impact of thrombin in surgery. Semin Thromb Hemost, 32(Suppl 1):98-110.

Muntean W, Zenz W, Finding K, et al. 1994. Inhibitor to factor V after exposure to fibrin sealant during cardiac surgery in a two-year-old child. Acta Paediatr, 83:84-7.

Omrix Biopharmaceuticals. Packet Insert for Evithrom. Last updated 2007. URL: http://www.fda.gov.libproxy.usc.edu/cber/label/ evithromLB.pdf.

Ortel TL, Charles LA, Keller FG, et al. 1994. Topical thrombin and acquired coagulation factor inhibitors: clinical spectrum and laboratory diagnosis. Am J Hematol, 45:128-135.

Ortel TL, Mercer MC, Thames EH, et al. 2001. Immunologic impact and clinical outcomes after surgical exposure to bovine thrombin. Ann Surg, 233:88-96.

Patterson C, Stouffer GA, Madamanchi N, et al. 2001. New tricks for old dogs: nonthrombotic effects of thrombin in vessel wall biology. Circ Res, 88:987-97.

Pavlovich CP, Battiwalla M, Rick ME, et al. 2001. Antibody induced coagulopathy from bovine thrombin use during partial nephrectomy. J Urol, 165:1617.
Poynton AR, Nelson MC, McCance SE, et al. 2003. Bovine thrombin induces an acquired coagulopathy in sensitized patients undergoing revision spinal surgery: a report of two cases. Spine, 28:E221-3.

Rapaport SI, Zivelin A, Minow RA, et al. 1992. Clinical significance of antibodies to bovine and human thrombin and factor $\mathrm{V}$ after surgical use of bovine thrombin. Am J Clin Pathol, 97:84-91.

Sabel M, Stummer W. 2004. The use of local agents: Surgicel and Surgifoam. Eur Spine J, 13(Suppl 1):S97-101.

Sands JJ, Nudo SA, Ashford RG, et al. 2000. Antibodies to topical bovine thrombin correlate with access thrombosis. Am J Kidney Dis, 35:796-801.

Sarfati MR, Dilorenzo DJ, Kraiss LW, et al. 2004. Severe coagulopathy following intraoperative use of topical thrombin. Ann Vasc Surg, 18:349-51.

Savage WJ, Kickler TS, Takemoto CM. 2007. Acquired coagulation factor inhibitors in children after topical bovine thrombin exposure. Pediatr Blood Cancer, 49:1025-9.

Schoenecker JG, Johnson RK, Lesher AP, et al. 2001. Exposure of mice to topical bovine thrombin induces systemic autoimmunity. Am J Pathol, 159:1957-69.

Schwartz M, Madariaga J, Hirose R, et al. 2004. Comparison of a new fibrin sealant with standard topical hemostatic agents. Arch Surg, 139:1148-54.

Spero JA. 1993. Bovine thrombin-induced inhibitor of factor V and bleeding risk in postoperative neurosurgical patients. Report of three cases. J Neurosurg, 78:817-20.

Streiff MB, Ness PM. 2002. Acquired FV inhibitors: a needless iatrogenic complication of bovine thrombin exposure. Transfusion, 42:18-26.

Taylor LM,Jr, Mueller-Velten G, Koslow A, et al. 2003. Prospective randomized multicenter trial of fibrin sealant versus thrombinsoaked gelatin sponge for suture- or needle-hole bleeding from polytetrafluoroethylene femoral artery grafts. J Vasc Surg, 38:766-71.

Timmerman L. Bloomberg News. FDA allows ZymoGenetics to skip trial of spray drug, saving time and money. March 7, 2007, URL: http://seattletimes.nwsource.com/html/biotech/2003605976_ webzymo07.html.

U.S. Food and Drug Administration. FDA News. August 28, 2007. URL: http://www.fda.gov/bbs/topics/NEWS/2007/NEW01690.html.

Wagner WR, Pachence JM, Ristich J, et al. 1996. Comparative in vitro analysis of topical hemostatic agents. $J$ Surg Res, 66:100-8.

Weaver F, Lew W, Granke K, et al. 2008. A comparison of recombinant thrombin to bovine thrombin as a hemostatic ancillary in patients undergoing peripheral artery bypass and arteriovenous graft procedures. in press.

Zehnder JL, Leung LL. 1990. Development of antibodies to thrombin and factor $\mathrm{V}$ with recurrent bleeding in a patient exposed to topical bovine thrombin. Blood, 76:2011-6.

Zymogenetics. Packet Insert for Recothrom. Last updated January 2008. 
